\title{
Data Monitoring of Student Attendance at Bina Nusantara University Using Control Charts
}

\author{
Heruna Tanty ${ }^{1}$; Anita Rahayu ${ }^{2}$ \\ ${ }^{1,2}$ Department of Statistics, Bina Nusantara University, Jakarta
}

\begin{abstract}
The need of data monitoring of student attendance by tapping on the machine Radio Frequency Identification (RFID) provides several advantages. But sometimes there are some students do not attend class after tapping. It is a problem faced by university because of the lack of correspondence between the numbers of students who are tapping the number of students who attend class. Because of these problems, then conducted research on monitoring of correspondence between the number of students tapping on RFID machine with the number of students who attend class. In addition, from the observed data, can also be used to monitor the attendance of students at Bina Nusantara university using control charts. The long-term goal of this research is to reduce the level of fraud and monitor the attendance of students in class. The sample in this study are 04PHT (Computer Science), 04 PJM (Information Systems), 02 PBS (Civil Engineering), 02 PEU (Graphic Design New Media), and 04 PBO (Marketing Communication). From this research results, concluded that the $p$ control chart, for the absence of the characteristic number of students in the fifth classes under controlled conditions. Furthermore, concluded also that the $p$ control chart, to characteristic number of students cheating in class 04 PHT courses basic communication networks and systems of data under controlled conditions. A process is said to be controlled if the value is within the interval statistics UCL (Upper Control Limit) and LCL (Lower Control Limit).
\end{abstract}

Keywords: attendance, control charts, descriptive statistics, monitoring, radio frequency identification

\section{Introduction}

Attendance is one measure whether a lecture in accordance with properly or not. The attendance of students determines if they are actively following the lecture or not. Even in some institutions, student attendance determines whether they are eligible to take the test or not.

Recording and monitoring of student attendance in lectures is one of the activities that can be implemented using information technology. In the field of education, information technology plays a role in teaching methods, learning tools, competency standards, decision support system, educational facilities, educational management tools, and educational infrastructure [1]. Attendance information system allows users to record its attendance in the system. One of the information technologies that can be used is by using Radio Frequency Identification (RFID). Recording the attendance data using RFID has advantages, the data recording process easy and student attendance information that can be monitored in real time. Another advantage is the ease of the services available to monitor academic class's filled and empty class.

Not always have the advantage of information technology sophistication. Weakness recording attendance data using RFID can be viewed in terms of monitoring. If faculty does not monitor the correspondence between the numbers of students tapping the number of students who attend class, there will be the possibility of some students to commit fraud. Cheating they can do is not get in and did not follow the lectures in class after tapping. Therefore, to reduce the level of fraud on the student's attendance in class, then do research on monitoring student attendance data at Bina Nusantara University using a control chart. Control chart is a chart that provides an overview of the behavior of a process. Control chart is used to understand whether a process running in a controlled environment or not. Control chart is used are variable and attribute control charts. Variable control chart used to monitor the characteristics of student attendance, while the attribute control chart is used to monitor the characteristics of the number of students who commit fraud.

\subsection{Control Charts}

\section{Literature Study}

Control chart is one component of the seven tools in Statistical Quality Control (SQC) and is a chart that provides an overview of the behavior of a process. Control chart is used to understand whether a process running in a controlled environment or not. A process that is fairly stable, but goes beyond the expected limits, should be repaired immediately to find the cause in order to get the fundamental improvement. 


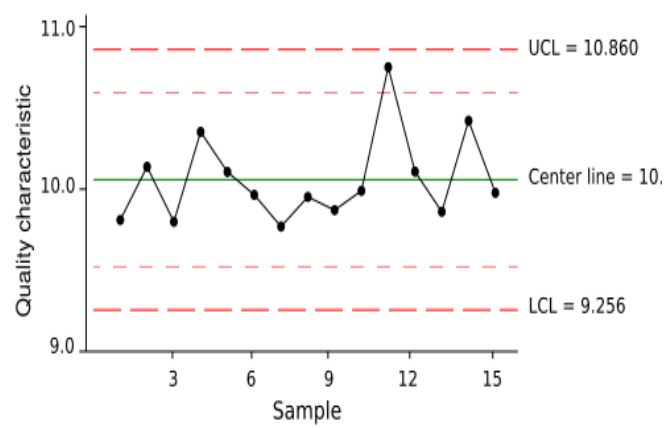

Fig 1. Example of Control Chart

Based on the number of quality characteristics are measured, control chart is divided into two kinds, namely the univariate and multivariate control chart [3]. Univariate control chart is used if there is only one quality characteristics are measured, while the multivariate control chart is used if the use of two or more related quality characteristics together. Univariate control chart can be divided into two types, namely variable and attribute control charts.

\section{a. Variable Control Chart}

Variable control chart based on characteristics derived from measurement results. There are all types of variables control chart [2].
(1) $\bar{x}$ and R control chart

Formula UCL, CL, and LCL for $\bar{x}$ control chart :

$$
\begin{aligned}
U C L & =\bar{x}+A_{2} \bar{R} \\
& = \\
C L= & x \\
& = \\
C L & =\bar{x}-A_{2} \bar{R}
\end{aligned}
$$

Formula UCL, CL, and LCL for R control chart :

$$
\begin{aligned}
& U C L=\bar{R} D_{4} \\
& C L=\bar{R} \\
& L C L=\bar{R} D_{3}
\end{aligned}
$$

(2) $\bar{x}$ and $\mathrm{S}$ control chart

Formula UCL, CL, and LCL for $\bar{x}$ control chart :

$$
\begin{aligned}
& U C L=\bar{x}+\frac{3 \bar{S}}{c_{4} \sqrt{n}} \\
& C L=\bar{x} \\
& L C L=\bar{x}-\frac{3 \bar{S}}{c_{4} \sqrt{n}}
\end{aligned}
$$

Formula UCL, CL, and LCL for S control chart :

$$
\begin{aligned}
& U C L=B_{4} \bar{S} \\
& C L=\bar{S} \\
& L C L=B_{3} \bar{S}
\end{aligned}
$$

\section{b. Attribute Control Chart}

Attribute control chart based on characteristics derived from the calculation. There are all types of attribute control chart [2]. 
- p control chart

$U C L=\bar{p}+3 \sqrt{\frac{\bar{p}(1-\bar{p})}{n}}$
$C L=\bar{p}$
$L C L=\bar{p}-3 \sqrt{\frac{\bar{p}(1-\bar{p})}{n}}$

\section{Research Methodology}

The data used in this study is primary data obtained from observations between the number of students tapping on RFID machines and the number of student's attendance at Bina Nusantara University. The sample used in this study is as much as 5 class, which consists of 04PHT (Computer Science), 04 PJM (Information System), 02PBS (Civil Engineering), 02PEU (DKV New Media), and 04 PBO (Marketing Communication). For each class, data collection was done in three courses, and each course is done as much as 3 data collection sessions. So the amount of data used in this study is a $3 \times 3 \times 5=45$ data. There is a flow chart used in this study.

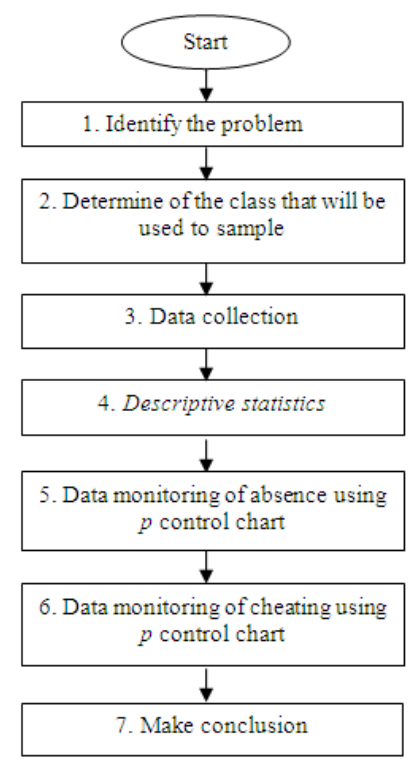

Fig 2. Flow Chart of Research

\section{Research Results}

Determination of the class that is used as a sample at Bina Nusantara University has five courses consisting of undergraduate programs, undergraduate programs (BINUS online learning), undergraduate programs (double degree), undergraduate programs (international), and graduate programs (business school). In this study, using a program of undergraduate study programs, this is because these programs demand a lot more when compared with four other programs.

Undergraduate programs have seven faculties where each faculty is composed of several departments. The total number of undergraduate majors in as many as 29 major programs. Here is a list of faculty and majors for undergraduate programs at Bina Nusantara University.

Table 1. Faculty and Undergraduate Programs Department at Bina Nusantara University

\begin{tabular}{|c|l|l|}
\hline No. & \multicolumn{1}{|c|}{ Faculty } & \multicolumn{1}{c|}{ Department } \\
\hline 1. & Economics and Communication & 1. Accounting \\
& & 2. Finance \\
& & 3. Marketing communication \\
\hline 2. & Engineering & 4. Hotel management \\
& & 5. Architectural engineering \\
& & 6. Computer engineering \\
& & 7. Civil engineering \\
\hline
\end{tabular}




\begin{tabular}{|c|l|ll|}
\hline 3. & School of Computer Science & 9. & Mobile application and technology \\
& & 10. & Game application and technology \\
& & 11. & Computer science \\
& & 12. & Double degree in computer science and mathematics \\
\hline 4. & School of Design & 13. & Double degree in computer science and statistics \\
& & 14. & DKV animation \\
& & 15. & DKV creative advertising \\
\hline 5. & School of Business and Management & 16. & DKV new media \\
\hline 6. & School of Information System & 17. & Interior design \\
& & 18. & International business and management \\
& & 19. & Accounting information systems \\
& & 20. & Computerized accounting \\
\hline 7. & Humanities & 22. & Information system \\
& & 23. & Double degree in information systems and accounting \\
& & 24. & Business law \\
& & 25. & China language \\
& & 26. & English language \\
& & 27. & International relations \\
& & 28. & Japanese language \\
\hline
\end{tabular}

To determine the number of faculty that will be used as a sample, it can be used the following Slovin formula.

$n=\frac{N}{1+N \alpha^{2}}$ in this study, $\mathrm{N}$ is the number of faculty and $\alpha$ is 0,2 . So :

$n=\frac{7}{1+7(0,2)^{2}}=\frac{7}{1+7(0,04)}=\frac{7}{1+0,28}=\frac{7}{1,28}=5$

Based on the calculation above Slovin formula can be concluded that there is a faculty of seven undergraduate programs at Bina Nusantara University, will be taken as samples 5 faculty research. The determination of the faculty conducted by simple random sampling technique using a random number table, where each sample (in this case each faculty) has an equal chance of being drawn.

Table 2. Five Faculties Selected Using Simple Random Sampling Techniques

\begin{tabular}{|c|c|l|}
\hline No. & Number of Faculty & \multicolumn{1}{|c|}{ Faculty } \\
\hline 1. & 02 & School of Computer Science \\
\hline 2. & 05 & School of Information System \\
\hline 3. & 01 & Engineering \\
\hline 4. & 03 & School of Design \\
\hline 5. & 00 & Economics and Communication \\
\hline
\end{tabular}

Based on Table 2., it can be concluded that the five faculties which will be used as the sample in this study is the school of computer science faculty, school of information systems, engineering, school of design, and the faculty of economics and communications. The faculty of each sample will be taken, namely the majors. The number of courses that are taken from any one department faculty. So in this study the total sample to be used is five majors.

Table 3. Five Departments Selected Using Simple Random Sampling Techniques

\begin{tabular}{|c|l|c|l|}
\hline No. & \multicolumn{1}{|c|}{ Faculty } & Number of Department & \multicolumn{1}{|c|}{ Department } \\
\hline 1. & School of Computer Science & 00 & Computer Science \\
\hline 2. & School of Information System & 00 & Information System \\
\hline 3. & Engineering & 00 & Civil engineering \\
\hline 4. & School of Design & 00 & DKV New Media \\
\hline 5. & Economics and Communication & 00 & Marketing Communication \\
\hline
\end{tabular}

On Table 3., seen that there are five departments that will be used the samples in this study, there are department of computer science, information systems, civil engineering, DKV new media, and marketing communication. Because there are many majors in the class, then only selected one class for each department. Making the class as a sample with nonprobability sampling technique.

Table 4. Five Classes Selected Using Nonprobability Sampling Technique

\begin{tabular}{|c|l|c|}
\hline No. & \multicolumn{1}{|c|}{ Department } & Class \\
\hline 1. & Computer Science & 04 PHT \\
\hline 2. & Information System & 04 PJM \\
\hline 3. & Civil engineering & 02 PBS \\
\hline 4. & DKV New Media & 02 PEU \\
\hline 5. & Marketing Communication & 04 PBO \\
\hline
\end{tabular}


In this study, three subjects used for each class with each course there are 3 meetings. So as much as the total data used: $3 \times 3 \times 5=45$ data.

\subsection{Descriptive Statistics}

The goal of descriptive statistics is to find a picture of the number of active students, the number of students attendance in the class, and the number of students in class tapping. Descriptive statistics were used in the form of tables and bar charts. There are the descriptive statistics the number of active students using SPSS software.

Table 5. Descriptive Statistics for the Number of Active Students

\begin{tabular}{|c|c|c|c|}
\hline & & & THE NUMBER OF ACTIVE STUDENTS \\
\hline \multirow{15}{*}{ DEPARTMENT } & \multirow{3}{*}{ Computer Science } & 1 & 69 \\
\hline & & 2 & 69 \\
\hline & & 3 & 69 \\
\hline & \multirow{3}{*}{ DKV New Media } & 1 & 49 \\
\hline & & 2 & 47 \\
\hline & & 3 & 48 \\
\hline & \multirow{3}{*}{ Information System } & 1 & 64 \\
\hline & & 2 & 66 \\
\hline & & 3 & 64 \\
\hline & \multirow{3}{*}{ Marketing Communication } & 1 & 49 \\
\hline & & 2 & 49 \\
\hline & & 3 & 49 \\
\hline & \multirow{3}{*}{ Civil Engineering } & 1 & 26 \\
\hline & & 2 & 26 \\
\hline & & 3 & 24 \\
\hline
\end{tabular}

Beside the descriptive statistics for the number of active students, can be also display descriptive statistics for the number of students attendance in the class and number of students tapping on machine RFID, so it can be seen the number of students who are not tapping and the number of students who commit fraud because the students tapping on machine RFID but not attendance in the class.

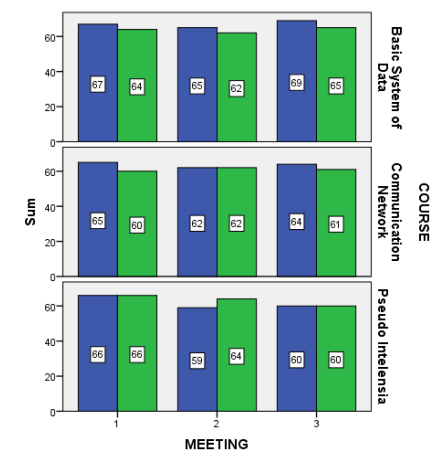

(a)

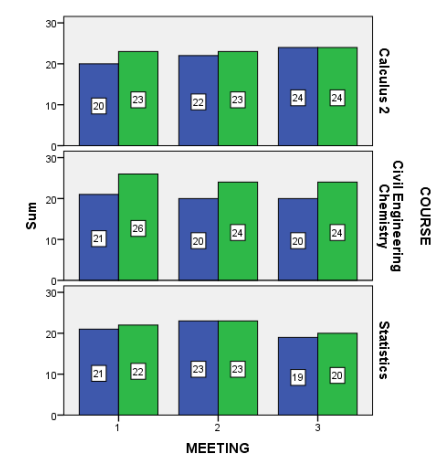

(c)

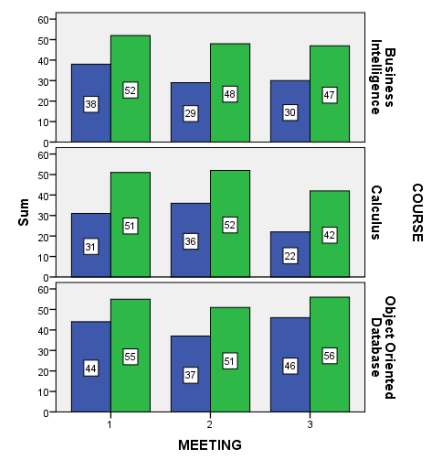

(b)

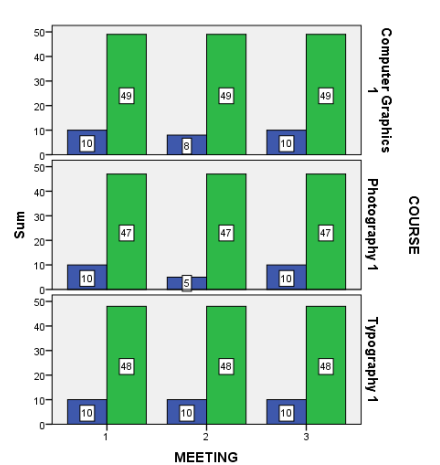

(d) 


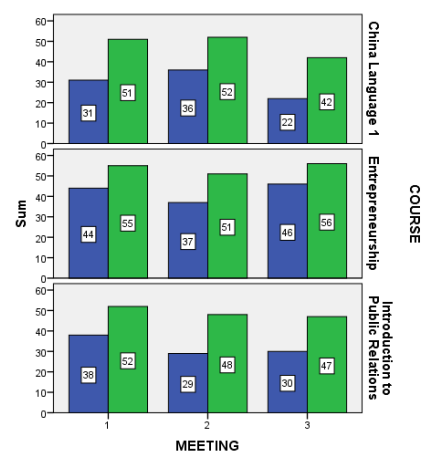

(e)

Fig 3. Bar Chart for Number of Students Tapping (blue) and Attendance in Class (Green)

(a) Class of 04PHT, (b) Class of 04PJM, (c) Class of 02PBS (d) Class of 02PEU, and (e) Class of 04PBO

Based on Fig 3., if the blue color of bar is higher than the green color of bar, it means that in the class on a particular subject and meeting a lot of students who commit fraud, meaning that the students tapping on machine RFID but not to be present in the class.

So it appears that the class of cheating, in terms of the number of students in class tapping but not present in the class is the class of 04 PHT. There are 5 students who commit fraud in 2 subjects (communication network) meeting to- 1 and there are 3 students who commit fraud in 2 subjects (communication network) 3rd meeting. In addition there are three students who commit fraud on the 3rd course (basic system data) meeting 1 st and 2nd, and there are 4 students who commit fraud on the 3rd course (basic system data) at a meeting to-3.

\subsection{Data Monitoring of Student Absence Using p Control Chart}

$\mathrm{p}$ control chart is used to monitor a characteristic that can be calculated. In this study, the characteristics of which can be counted is the number of student absences, which can be calculated by the number of active students subtracted the number of students who attend class. There are calculations of the UCL, CL, and LCL for each class using p control chart with Minitab software [4].
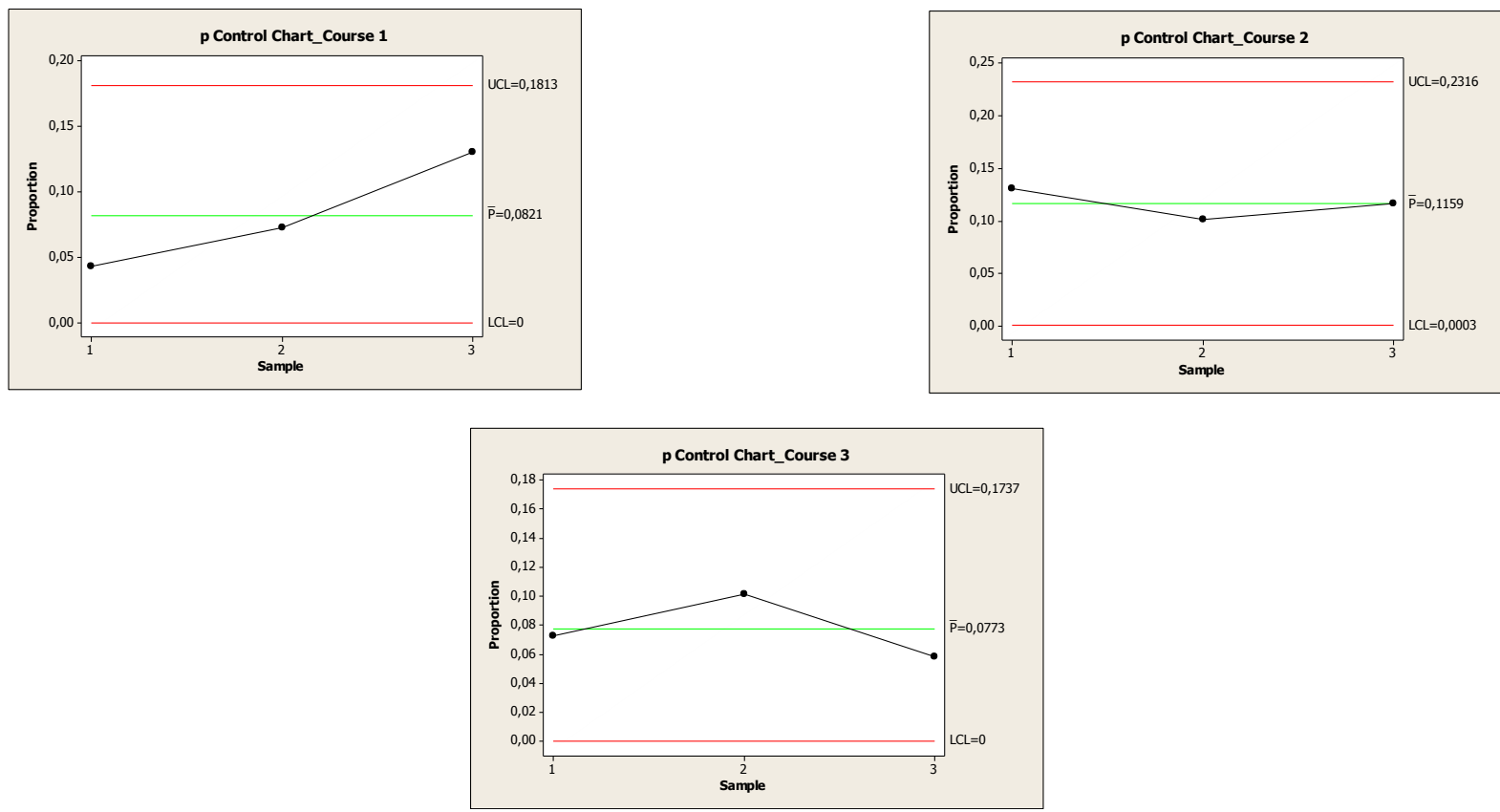

Fig 4. $\mathrm{p}$ Control Chart for Absence Characteristics in Class of 04PHT 

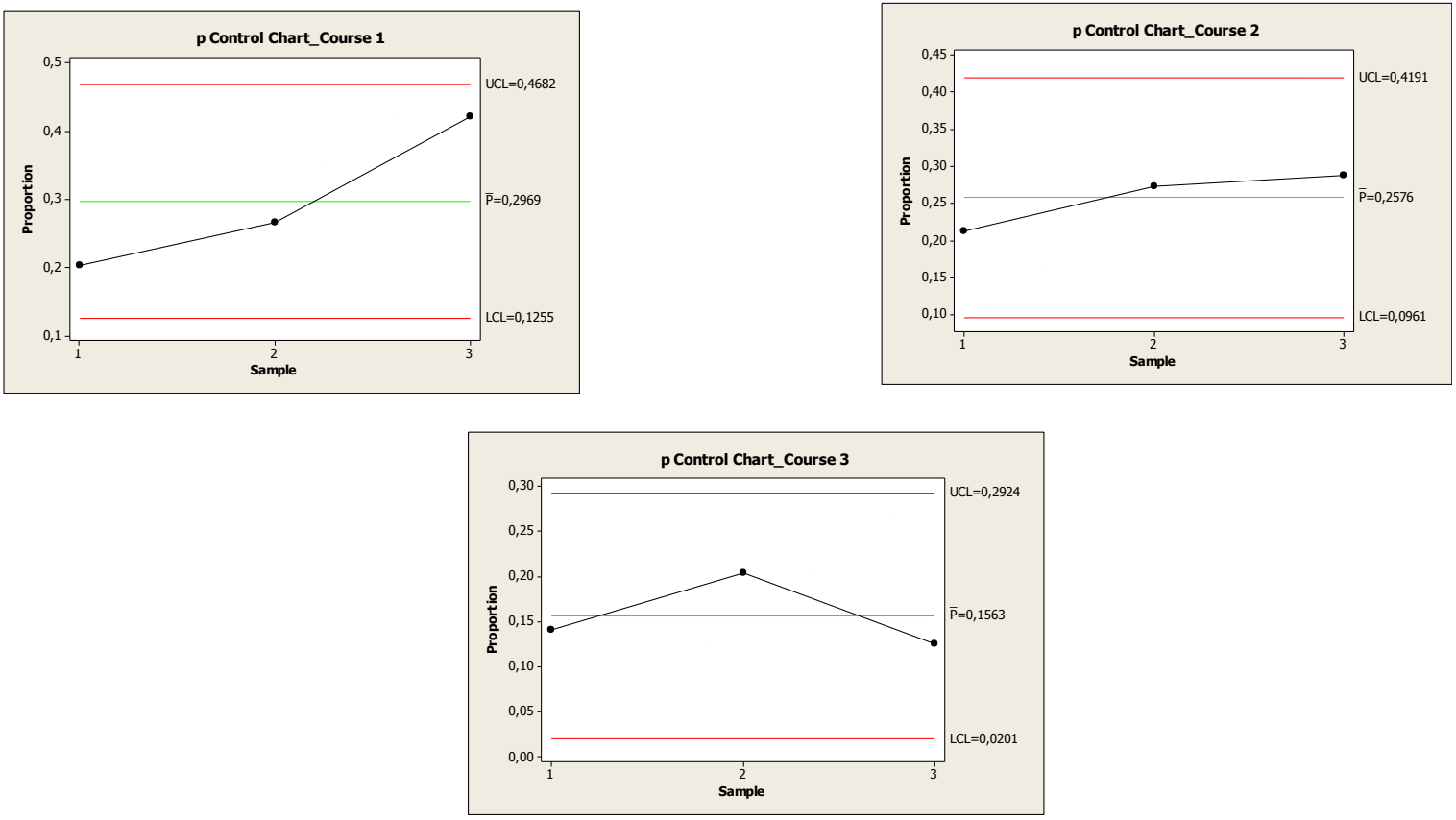

Fig 5. $p$ Control Chart for Absence Characteristics in Class of 04PJM
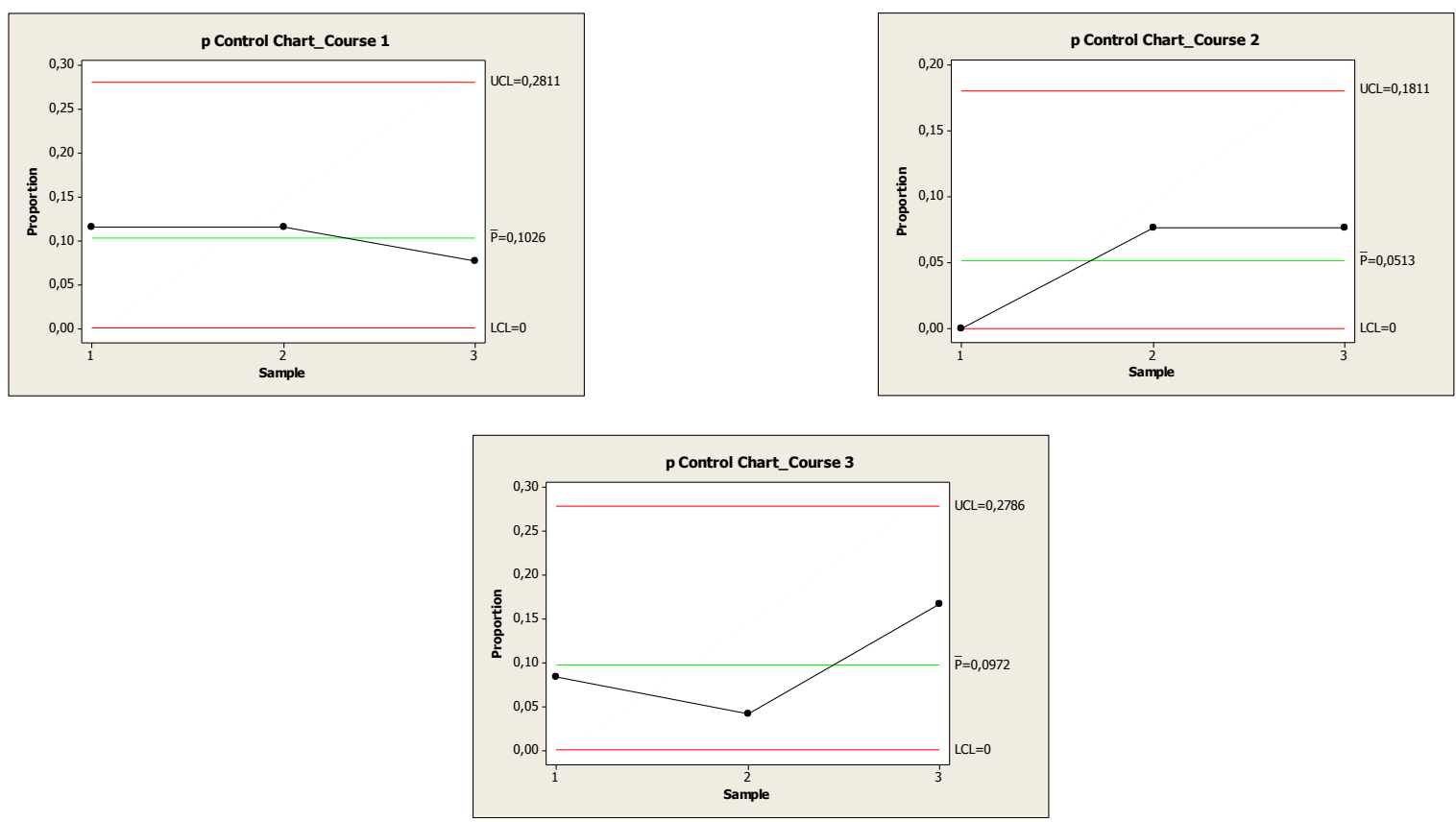

Fig 6. $p$ Control Chart for Absence Characteristics in Class of 02PBS 

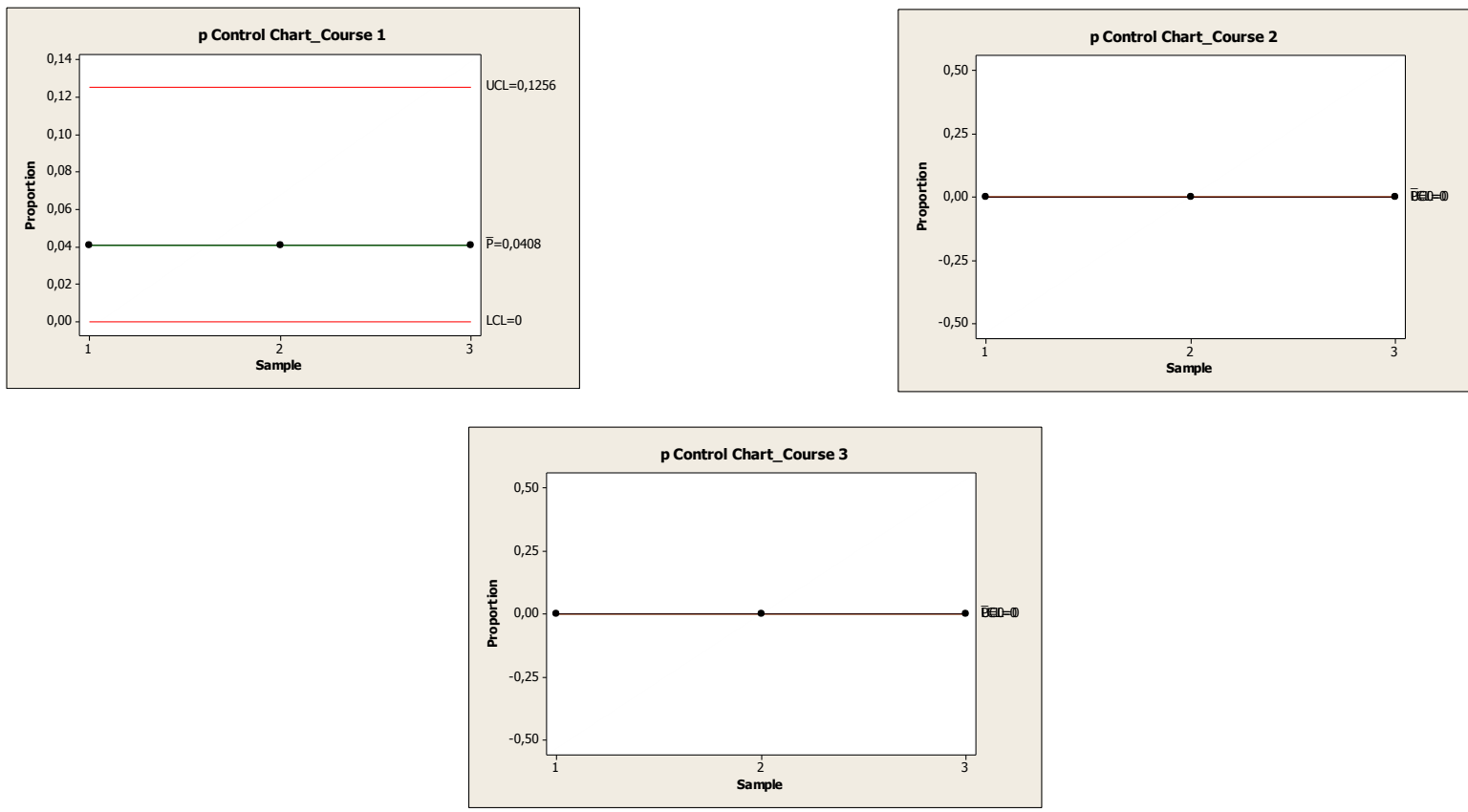

Fig 7. p Control Chart for Absence Characteristics in Class of 02PEU
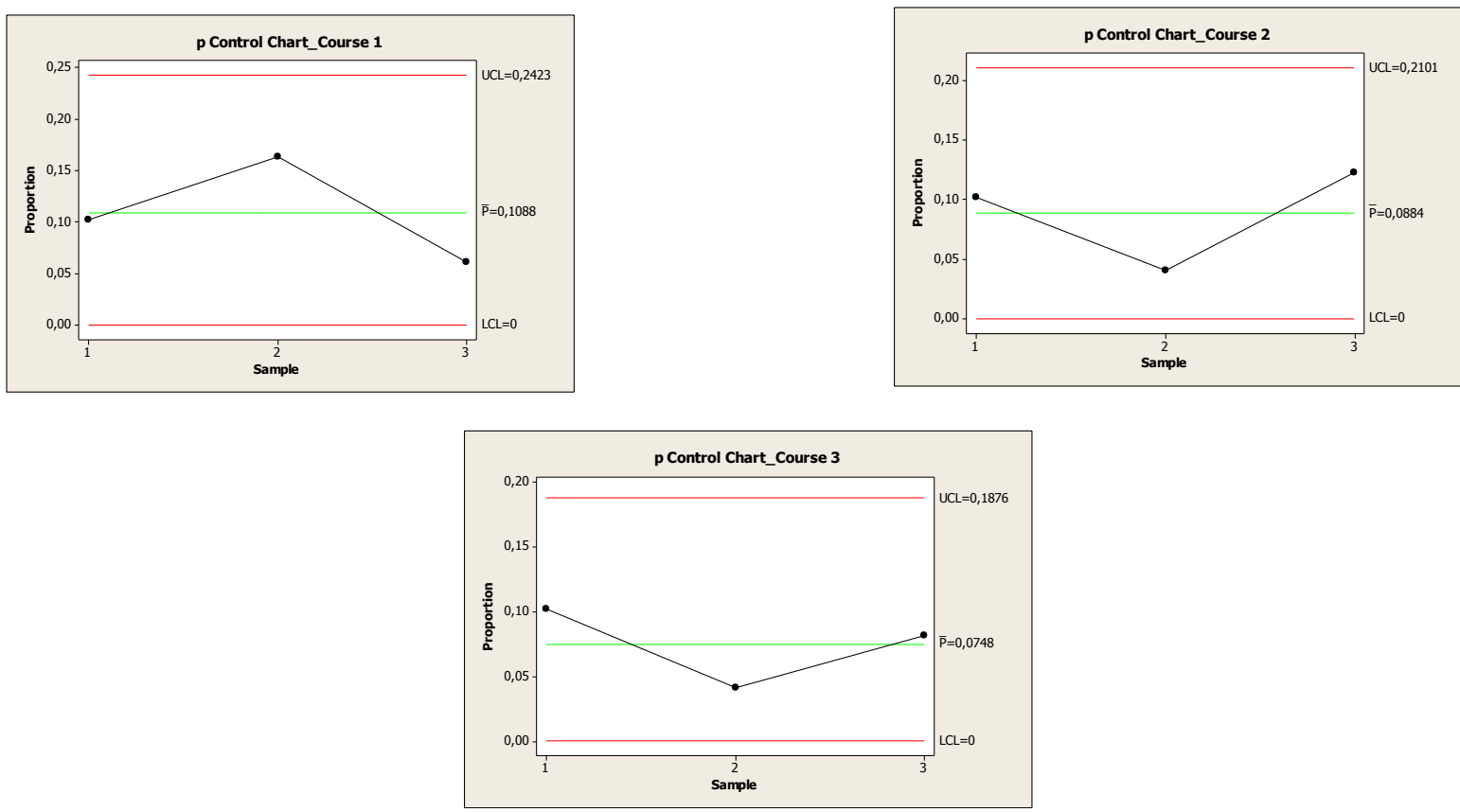

Fig 8. $p$ Control Chart for Absence Characteristics in Class of 04PBO

Based on Fig 4. until Fig 8. can be concluded that the p control chart, for absence characteristic in class 04 PHT, 04 PJM, 02 PBS, 02 PEU, and 04 PBO is controlled conditions. This is indicated by the statistical value (in this study are the average proportion between the number of students who do not present the number of active students) are in the interval UCL (Upper Control Limit) and LCL (Lower Control Limit).

\subsection{Data Monitoring Using p Control Chart}

In this study, the p control chart used in addition to the characteristics of absence, can be also used for cheating characteristics. In this case it means cheating the students tapping on machine RFID but not present in the class. Based on Fig 3. can be seen that the class that cheating is class of 04PHT, it can be shown with high 
blue color bar chart (number of students in class tapping) is higher than the green color bar chart (number of students present in class). The fraud occurred in the course communication network and basic system data.
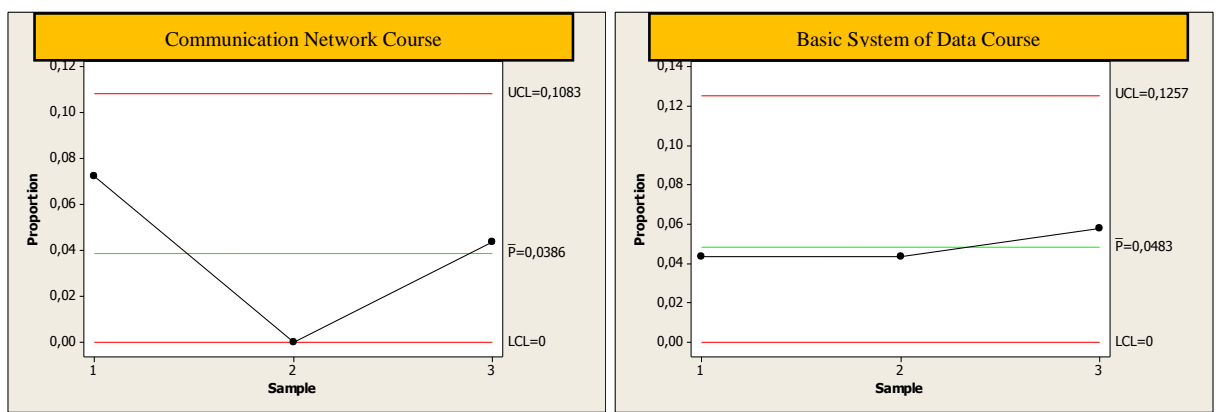

Fig 9. p Control Chart for Class of 04PHT

\section{Conclusions}

\section{Conclusions And Recommendations}

1. Based on the p control chart can be concluded that the characteristics of the number of absences for class of 04PHT, 04PJM, 02PBS, 02PEU, and 04PBO in controlled conditions (no observations were out of control).

2. Based on the p control chart can be concluded that the fraud amount for characterizing the class of 04PHT students on network communications courses and basic system data in controlled conditions (no observations were out of control).

\section{Recommendations}

Some recommendations related to the results of this study are:

1. When monitoring student attendance, need to do more research on the reasons for student cheating by tapping but not present in the class.

2. As a follow-up to this study, the lecturer can give warning to students who commit fraud. As well as lecturers should provide penalties reminder to all students who commit fraud.

3. To minimize the cheating student, it should be at every meeting, the lecturers always perform validation (match) between the number of students tapping and the number of students who attend class.

\section{References}

[1]. Bastian dan Reza A., Teknologi Informasi Pendidikan (Kedaulatan Rakyat, 2005).

[2]. Montgomery, D.C., Introduction to Statistical Quality Control. 07 (John Wiley \& Sons, Inc. , 2012). ISBN : 978-1118146811.

[3]. Pattihahuan S., Setiawan A., dan Sasongko, L.R., Penerapan Grafik Pengendali Berdasarkan Estimasi Fungsi Densitas Kernel Bivariat (Program Studi Matematika, Fakultas Sains dan Matematika, Universitas Kristen Satya Wacana, 2012). ISBN : 978-97917763-5-6.

[4]. Ryan B.F., Joiner B L., and Cryer J.D., Minitab Handbook. 06 (Cengage Learning, 2012). ISBN : 978-1133939443. 